\title{
Applicability of an interferometric optical fibre sensor for shallow landslide monitoring - Experimental tests
}

\author{
Vladislav Ivanov ${ }^{\mathrm{a}}$, Laura Longoni ${ }^{\mathrm{a}, *}$, Maddalena Ferrario ${ }^{\mathrm{b}}$, Marco Brunero $^{\mathrm{b}}$, Diego Arosio ${ }^{\mathrm{c}}$, \\ Monica Papini ${ }^{a}$ \\ a Department of Civil and Environmental Engineering, Politecnico di Milano, Piazza Leonardo da Vinci, 32, 20133 Milano, Italy \\ ${ }^{\mathrm{b}}$ Department of Electronics, Information and Bioengineering, Politecnico di Milano, via Ponzio, 34/5, 20133 Milano, Italy \\ ${ }^{c}$ Department of Chemical and Geological Sciences, University of Modena and Reggio Emilia, Via G. Campi 103, 41125 Modena, Italy
}

\section{A R T I C L E I N F O}

\section{Keywords:}

Optical fibre sensing

Shallow landslide

Experimental tests

Landslide monitoring

\begin{abstract}
A B S T R A C T
Optical fibre-based sensors have found a variety of applications throughout engineering and science in the measurement of strain and temperature. Current commercially available sensing technologies are able to provide strain measurements in the order of microstrain across tens of kilometres of range. The strong demand for reliable sensing tools in engineering geology allowed for the advancement of the optical fibre technology which has settled in this field during the past decade. Among the variety of sensing approaches, interferometric fibre optic sensors have rarely been tested for detection of ground movement. In this work we present the results of six laboratory scale experiments in which simulated rainfall induced shallow landslide model made up of noncohesive soil is equipped with a newly developed coherent fibre optic sensor. Results indicate that a phase of early precursors of instability could be identified by the sensors in all six experiments, two to eight minutes before slope failure. The sensing system proved to be reliable in detecting the evolution of slope stability at shallow depths of up to a few meters depending on the sensors' burial depth, hence stating the emergence of a simple and cost-effective approach for detailed strain monitoring. The proposed sensing technique could therefore provide a viable and cheaper alternative to commercially available optical fibre interrogators and furnish quantitative monitoring data for shallow landslide monitoring in soil-like materials. In order to be efficient for the detection of such failures with a significant precursory window, sensors should ideally be placed in the vicinity of a sliding surface or landslide boundary, which is an achievable task given the high sensing range and multiplexing capabilities of optical fibre sensors.
\end{abstract}

\section{Introduction}

The optical fibre technology has become indispensable, currently supporting a great deal of the world's internet connection, television, and telephone network. Optical fibre cables are designed to carry high quality data over long distances at unprecedented velocity. Apart from their dominant role in telecommunications, optical fibre cables have been successfully used as sensing devices due to the sensitivity of the propagating light signal to disturbances such as strain and temperature change. Hence, coupling an optical fibre cable with strain- and/or temperature change-inducing phenomena permits the process to be observed and, in some cases, quantified by the differences recorded between a forward propagating signal and its reflected counterpart.
The use of optical fibre sensors for monitoring slope stability phenomena has gained some strong interest during the past two decades. The most common sensing systems comprise Fibre Bragg Grating (FBG), Brillouin Optical Time Domain Reflectometry (BOTDR), and Brillouin Optical Time Domain Analysis (BOTDA). While FBG-based sensors provide discrete strain and temperature measurements at predefined locations, BOTDR/A measure strain and temperature change over the entire cable length for as many as several kilometres. Numerous works could be found throughout the literature which explore the applicability of these technologies as monitoring tools for landslides. Case studies could be distinguished according to the type of sensing technology, as previously described. In this field, the distributed sensors are much more valued due to the possibility of monitoring large areas with high

\footnotetext{
* Corresponding author.

E-mail addresses: vladislavivov.ivanov@polimi.it (V. Ivanov), laura.longoni@polimi.it (L. Longoni), maddalena.ferrario@polimi.it (M. Ferrario), marco.brunero@ polimi.it (M. Brunero), diego.arosio@unimore.it (D. Arosio), monica.papini@polimi.it (M. Papini).
} 
precision (Iten et al., 2008; Olivares et al., 2009; Wang et al., 2009; Iten et al., 2011; Hauswirth et al., 2013; Huntley et al., 2014; Zhu et al., 2014; Minardo et al., 2014; Zeni et al., 2015; Picarelli et al., 2015; Zhang et al., 2015; Sun et al., 2016; Michlmayr et al., 2017; Schenato et al., 2017; Kogure and Okuda, 2018; Zhang et al., 2018; Li et al., 2019; Papini et al., 2020). This category of sensors is followed by semidistributed systems which typically employ FBG sensors in series in applications such as optical fibre-based inclinometers (Yoshida et al., 2002; Ho et al., 2006; Li et al., 2010; Zhang et al., 2016). Finally, single FBG sensors find their place in monitoring smaller-scale instability phenomena in a variety of ingenious applications (Pei et al., 2011; Huang et al., 2012a; Huang et al., 2012b; Rajan et al., 2016). Further, works can be differentiated by the type of experimental environment. The majority of the works are carried out under controlled laboratory conditions in order to explore the ability of the sensors to detect precursory signals or to calibrate the strain measured to a certain displacement (Yoshida et al., 2002; Ho et al., 2006; Olivares et al., 2009; Wang et al., 2009; Li et al., 2010; Pei et al., 2011; Iten et al., 2011; Huang et al., 2012a; Huang et al., 2012b; Hauswirth et al., 2013; Schenato et al., 2012; Zhu et al., 2014; Minardo et al., 2014; Zeni et al., 2015; Picarelli et al., 2015; Rajan et al., 2016; Michlmayr et al., 2017; Schenato et al., 2017; Li et al., 2019; Papini et al., 2020). Field applications, however, have a non-negligible contribution to the research field as well (Iten et al., 2008; Pei et al., 2011; Huang et al., 2012a; Huang et al., 2012b; Hauswirth et al., 2013; Huntley et al., 2014; Zhu et al., 2014; Minardo et al., 2014; Zeni et al., 2015; Zhang et al., 2015; Lienhart, 2015; Sun et al., 2016; Kogure and Okuda, 2018; Zhang et al., 2018). Another distinctive feature is the mode of placement of the sensor. Depending on the geohazard, fibre optic (FO) sensors could be placed directly into the ground (Iten et al., 2008; Olivares et al., 2009; Wang et al., 2009; Hauswirth et al., 2013; Zhu et al., 2014; Zeni et al., 2015; Picarelli et al., 2015; Lienhart, 2015; Michlmayr et al., 2017; Schenato et al., 2017; Zhang et al., 2018; Papini et al., 2020) or conversely, attached to either a stabilizing structure or reinforcement, or coupled to a conventional monitoring tool such as an inclinometer (Yoshida et al., 2002; Ho et al., 2006; Li et al., 2010; Iten et al., 2011; Pei et al., 2011; Huang et al., 2012b; Minardo et al., 2014; Zeni et al., 2015; Zhang et al., 2015; Zhu et al., 2015; Zhang et al., 2016; Sun et al., 2016; Rajan et al., 2016; Kogure and Okuda, 2018; Li et al., 2019; Xu and Yin, 2016). Finally, the sensing technology can be distinguished by the type of strain induced on the cable. While in the majority of the studies, the measurand is the strain induced by the direct physical deformation of the cable (Yoshida et al., 2002; Ho et al., 2006; Iten et al., 2008; Olivares et al., 2009; Wang et al., 2009; Li et al., 2010; Iten et al., 2011; Pei et al., 2011; Huang et al., 2012a, 2012b; Hauswirth et al., 2013; Huntley et al., 2014; Zhu et al., 2014; Minardo et al., 2014; Zeni et al., 2015; Picarelli et al., 2015; Zhang et al., 2015; Lienhart, 2015; Zhu et al., 2015; Xu and Yin, 2016; Sun et al., 2016; Zhang et al., 2016; Schenato et al., 2017; Kogure and Okuda, 2018; Zhang et al., 2018; Li et al., 2019; Papini et al., 2020), some studies have emerged in which high frequency measurements allow for the detection of elastic waves in the acoustic and sub acoustic frequency range (Michlmayr et al., 2017; Huang et al., 2012b; Rajan et al., 2016; Schenato et al., 2017).

The cited works demonstrate the tendency to employ optical fibre sensors as a stability monitoring tool in two main ways: embedded directly underground and in some form of an alternative to the conventional monitoring systems, such as inclinometers. Results generally seem promising for the development of a complete monitoring system and thus research in the area still advances. This brings to the front an extremely important aspect of the current development of optical fibre sensors for slope stability monitoring. While many authors emphasize on the reduced costs and durability of the sensor itself (i.e., optical fibre cables), it has been seldom discussed that interrogators are, in fact, the exact opposite - costs can extend up to several tens of thousands of euro and are generally designed to work in a protected environment, such as the laboratory. This shortcoming plays a crucial role for the further development of optical fibre as monitoring systems and especially when an early warning system is to be the final outcome of the work, as constant presence of an interrogator on-site might be required. Even though a number of studies have been carried out on the use of optical fibre-based strain sensors, their use as an alternative to conventional instruments (e.g., inclinometers) has not yet reached a point of complete substitution. Schenato (2017) and Shanafield et al. (2018) discussed the need for further research into sensing mechanisms, hardware and the respective managing software, through testing new installations in order to promote the broader acceptance and applicability of optical fibre sensing in the field of geohazards.

In this work, we propose a simple and cost-effective approach that can be compared to BOTDA/R in terms of sensing capabilities. The sensing principle relies on interferometric "integral coherent measurements". The name derives from the sensing principle according to which, they yield an integral of the signal response over the entire length of the sensor. This sensing system proves to be suitable to provide an overall indication of the state of the entire monitored domain and yield indications of strain and temperature change with a high temporal resolution. Those sensors are said to be a worthy competitor to what is already established and commercially available instruments. Applications of this optical fibre sensing technology have demonstrated its efficiency in a variety of engineering fields and at different scales - from pipeline cavitation (Boffi et al., 2019) to structural health monitoring (SHM) (Di Luch et al., 2019). The application of this technology to slope stability monitoring could be an advancement with respect to current optical fibre monitoring technologies due to the potential of coherent optical fibre sensors to provide high sensitivity measurements at a reduced cost. Successful application of a similar sensing technology for landslide monitoring has been presented by Brückl et al. (2013) and Lienhart (2015) who installed a three-sensor-based rosette featuring a low coherence Michenlson interferometer in a slow-moving deep seated mass movement. Instead, optical fibre sensing has rarely been applied for monitoring of shallow landslides. Only recently Schenato et al. (2017) and Michlmayr et al. (2017) explored such applications with experimental tests on reduced scale physical models. Shallow landslides could represent a severe threat to people, property, and infrastructure. Such slides can be widespread, have high velocities, and induce damage that could have enormous direct socio-economic impacts (Montgomery and Dietrich, 1994) or act as input for heavy sediment transport, resulting in secondary issues of non-negligible importance (Longoni et al., 2016; Papini et al., 2017; Ivanov et al., 2020a). The primary triggering factor for those phenomena is the heavy precipitation and the consequent redistribution of water within the soil. Risk mitigation measures involve the definition of rainfall thresholds over which a given area is considered to be susceptible to slope failures. Rainfall thresholds have been integrated with additional information that complements the meteorological factor (e.g., soil moisture) in order to improve the predictive capabilities of this approach. However, quantitative information regarding slope deformation has rarely been integrated with rainfall thresholds when designing early warning systems (Pecoraro et al., 2019). In a recent work, Abraham et al. (2020) demonstrated an improvement of a shallow landslide early warning system by complementing rainfall intensity-duration thresholds with MEMS-based tilt meters. Therefore, the addition of a reliable monitoring tool that could effectively detect instants of instability could certainly be of value to the better understanding of underlying processes, evaluation of stability thresholds, and site-specific calibration of stability models.

The main goals of this work are (1) to demonstrate the functionality of the proposed low-cost optical fibre sensors in reflecting the temporal and spatial development of instability (2) to evaluate their ability to detect instability precursors in monitoring rainfall induced shallow landslides. To this end, we present the results of six experiments, carried out on a reduced-scale rainfall triggered shallow slope failure simulation. The slope is equipped with interferometric optical fibre sensors, featuring a different layout, according to the experiment, a TDR probe 
for soil moisture monitoring, and video cameras for visual inspection. The obtained signals are processed in the time domain and interpreted in terms of the sensors' capacity to identify the different phases of slope failure. The study builds upon preliminary results presented in Papini et al. (2020), based on a subset of this dataset where the focus was the comparison of the signals retrieved by the proposed sensor and an OFRD-based technology.

\section{Methods}

\subsection{Interferometric optical fibre sensing system}

The coherent optical fibre sensing solution exploited in this work relies on a novel phase-diversity coherent detection scheme (Martinelli and Ferrario, 2013) which combines a $3 \times 3$ optical coupler with standard optical fibres terminated with Faraday Rotator Mirrors (FRMs), as shown in Fig. 1. The incident light wave is divided by the $3 \times 3$ coupler and sent into the sensing and reference arms. In the sensing arm, the interaction between the measurand (i.e., the pressure exerted by the moving soil) with the sensing fibre, causes a strain, $\Delta \mathrm{L}$, of the fibre itself which, in turn, results in a perturbation of the phase, $\Delta \theta(\mathrm{t})$, of the propagating optical signal. Thanks to the adopted phase-diversity scheme the phase behaviour, $\Delta \theta(\mathrm{t})$, can be retrieved in a completely passive way without the need of an active feedback for quadrature point stabilization as in conventional fibre optic interferometry (Martinelli, 1989). Hence, the proposed detection scheme allows one to overcome issues that, until recently, have limited the actual in-situ applicability of this technology that features cost-effectiveness, broadband and high sensitivity. The versatility of the proposed sensing technique has already been widely proven in a variety of engineering contexts, for example, for impact damage diagnostic in aeronautic structures, cavitation onset detection in hydraulic pipes, as well as for predictive maintenance applications in industrial production process (Boffi et al., 2019; Sbarufatti et al., 2017; Ferrario et al., 2016). The sensing scheme can be defined as "integral" as each single measurement provides the sum of the phase difference accumulated by the optical signal during its propagation along the entire length of the sensing cable $(\Sigma \Delta \theta(t))$. The main advantage of this approach is that, thanks to its integral nature, sensitivity in the order of $\mu \varepsilon$ in strain measurement is easily achieved even with off-the shelf acquisition boards (Ferrario et al., 2016). This turns out to be a reliable and affordable solution with costs reduced down to an order of magnitude with respect to commercially available FO interrogators. Moreover, the simplicity of its design allows for the relatively easy transportation and potential installation on-site - a feature of imperative importance for continuous landslide monitoring.

\subsection{Experimental setup}

The experimental work was accommodated in the laboratory of Applied Geology in the Lecco Campus of Politecnico di Milano (Scaioni et al., 2018; Hojat et al., 2020; Ivanov et al., 2020b). A $2 \mathrm{~m}$ by $0.8 \mathrm{~m}$ steel structure flume with a modifiable inclination was designed for the landslide simulations (Fig. 2). Its inclination could be increased up to

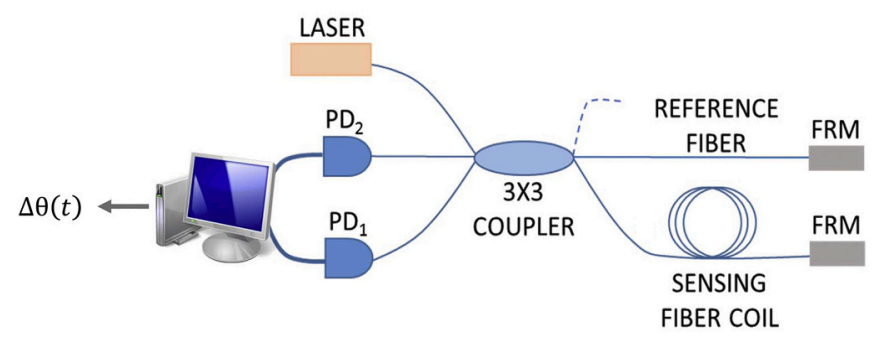

Fig. 1. Schematic representation of the fibre optic coherent sensing principle. $\left(\mathrm{PD}_{\mathrm{i}}=\right.$ Phase difference; FRM = Faraday Rotator Mirror $)$.

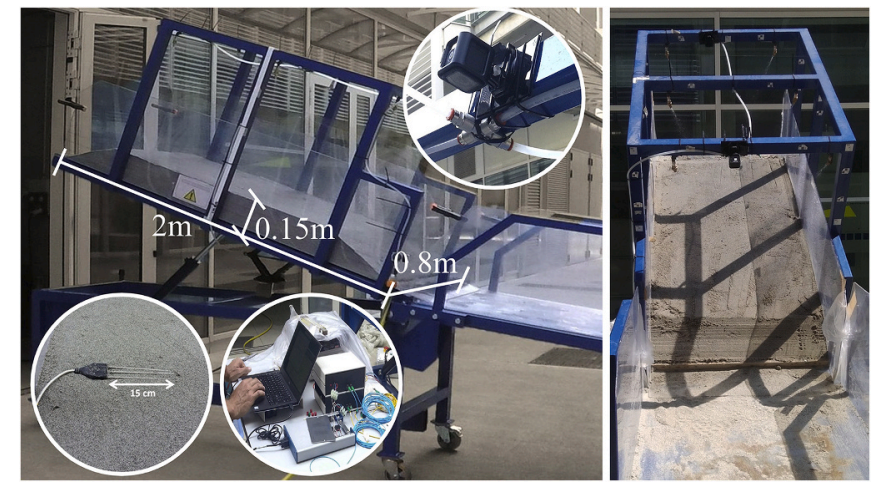

Fig. 2. Landslide simulator and monitoring tools. a) side view; b) front view.

$45^{\circ}$. A geogrid is installed on the bottom of the channel in order to ensure a grip between the landslide material and the flume. Homogeneous uniformly sized fine sand of $d_{50}=0.35 \mathrm{~mm}$ was used for the construction of the landslide body. Sand was placed in the channel in layers of $5 \mathrm{~cm}$ in order to achieve a uniform compaction across the flume for a total depth of $15 \mathrm{~cm}$. The degree of compaction of the material was imposed by a fixed relationship between the volume occupied by each layer and the mass of the constituting material. Porosity of the landslide body during various experiments therefore ranged between $50 \%-52 \%$. The structure is equipped with a sprinkler system for rainfall simulation necessary to trigger the soil failure. Its discharge is controlled by means of a pressure reduction valve and a pressure-discharge characteristic curve of the nozzles, provided by the manufacturer. The cone-shaped sprinkler jets were oriented at different angles towards the surface in order to ensure uniform distribution of the discharge. Volumetric water content is monitored during the experiment with a TDR probe inserted within the soil (Fig. 2). The probe has a range of $15 \mathrm{~cm}$ in diameter and could give an indication of the average volumetric water content for a representative volume of terrain depending on its placement. The vertical placement of the probe (experiments 1 and 2) in the upper part of the slope did not represent well the soil moisture status and was thus positioned horizontally in the successive tests. The entire landslide process is recorded visually by means of two action cameras attached to the steel structure through a time-lapse image acquisition. Two different experimental setups were created with a different placement of the optical fibre sensors. Setup I (Fig. 3a) features two optical fibre cables installed at different depths $(10 \mathrm{~cm}-\mathrm{A}$ and $15 \mathrm{~cm}-\mathrm{B})$ near the toe of the slope in a direction perpendicular to the expected direction of failure. The cables were fixed on the side of the flume in order to ensure that the recorded strain occurs within the landslide body. Configuration II (Fig. 3b) instead involves the placement of three optical fibre cables, all at the same depth $(7.5 \mathrm{~cm})$ but at three different positions along the slope - at the lower (A), intermediate (B), and upper sections (C) of the slope, respectively. Four experiments were carried out with setup I and two with setup II. Readings from the sensors were recorded and stored for post-processing and interpretation. Optical fibres are sensitive to both strain and temperature effects and proper compensation solution should be adopted. Yet, in the present experimentation it was considered that the temperature change has a rather limited effect on the phase difference with respect to the soil-induced strain and thus compensation was not considered necessary.

\subsection{Experimental conduct}

After soil preparation, the adjustable platform is increased to form the desired inclination and the sprinklers are switched on. The process is then monitored until slope failure occurs. A comparative table is provided to summarize the various cases (Table 1 ). After sprinkler activation, progressive soil saturation eventually led to slope failure in 25-30 

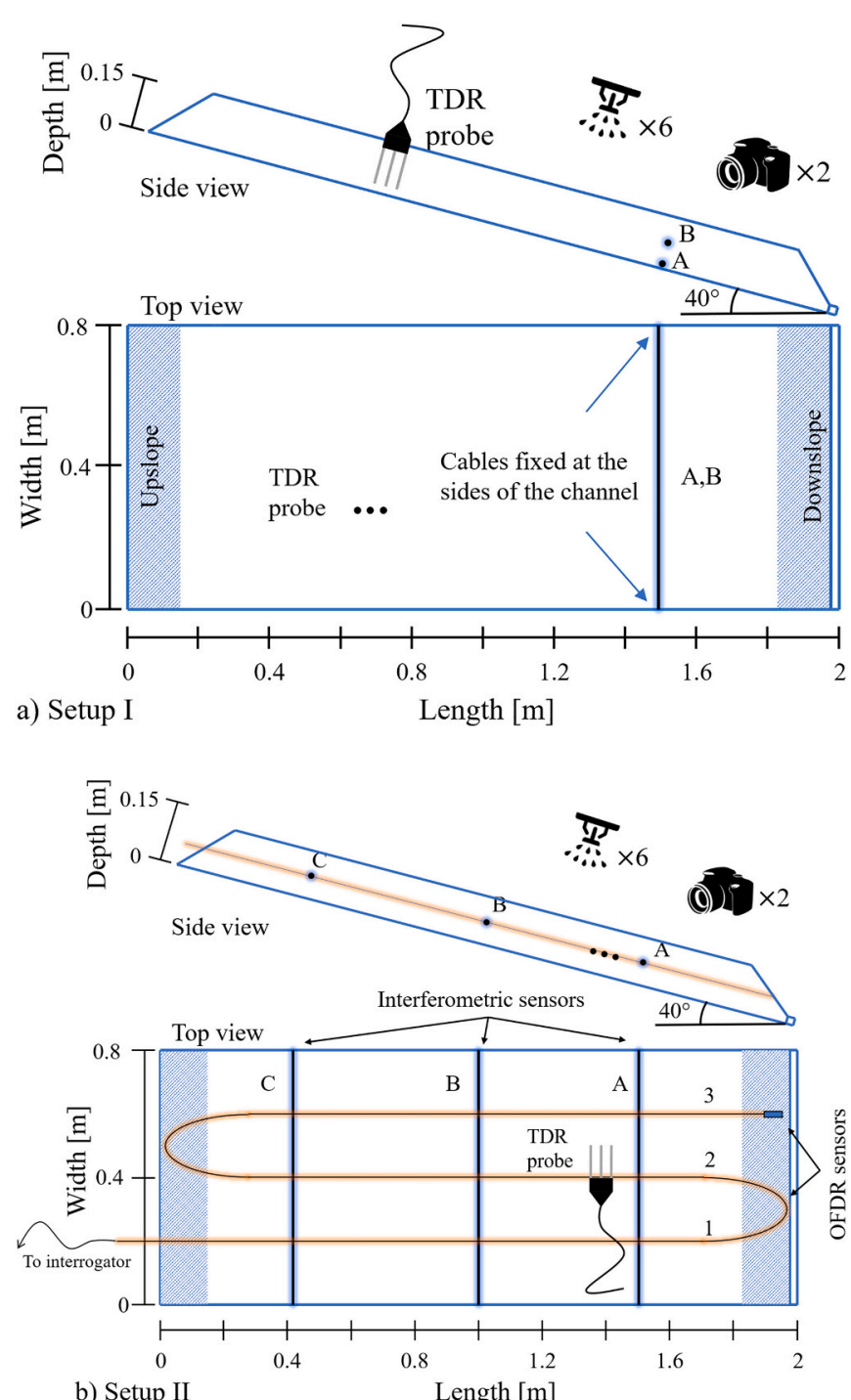

Fig. 3. Plan and side views of experimental schemes I (a) and II (b). A, B, and C indicate the different sensors inserted within the slope. 1, 2, and 3 indicate the OFDR sensors used for validation of the results.

min. Failure generally started from the lowermost sections of the slope and continued in a retrogressive manner towards the upslope end of the channel. Initially, the entire slope was stable and did not show any signs of deformation or instability. Upon destabilization, the soil exerted thrust on the optical fibre sensor. Soon after, cracks appeared on the surface of the sand layer and their aperture extended up to a failure. This process developed into a discontinuous failure, where blocks of material detached from the main mass forming curvilinear sliding surfaces.

\subsection{Data analysis}

The integral phase difference, $\Sigma \Delta \theta(\mathrm{t})$, recorded during the experiments was further processed in order to try to identify the most significant phases of instability development. The average of the raw signal was first subtracted from the data. A highpass filter was then applied in order to remove low frequency oscillations which could lead to a misleading interpretation of the recorded signal. Peak analysis was carried out on the resulting signal, which helped for the identification of peak trends in the dataset. In particular, we identified episodes involving the increase of peak prominence as well as a decrease in peak width. Peak prominence has been defined as the minimum vertical distance that the signal must descend on either side of the peak before either climbing back to a level higher than the peak or reaching an endpoint (Mathworks, 2019). The width of the peak is computed as the distance between the points to the left and right of the peak, measured at half the peak prominence (Mathworks, 2019). An increasing peak-to-width ratio therefore indicates a simultaneous increase in amplitude and frequency of the recorded signal. Consecutive peaks corresponding to the progressive and steady increase of the peak-to-width ratio are bound by an envelope, indicated by a red line in the following section. The episodes outlined with this procedure precede the first failure of the soil body and thus serve as a marker of the initiation of instability.

\section{Results}

Results of the data analysis are presented in Fig. 4a-f. Each letter refers to one of the experiments listed in Table 1 . The blue line in the graph represents the signal recorded by the interferometric FO sensors, processed with a highpass filter, while the red line describes the increase in peak prominence to width ratio, marking the development of instability. TDR data illustrates the rates of change in volumetric water content during the experiments until the probe is exposed by soil failure.

\subsection{Temporal response}

Interpretation of the signal response has been carried out with reference to the excellent work of Schenato et al. (2017), who demonstrate the results of a single experiment involving four branches of longitudinally placed OFDR sensors. Apart from the sensing technology and modality of placement, their experimental setup is larger in size and involves two different layers of soil, where the sensors were placed on the interface between the two layers. The authors report a tentative identification of four evolutionary phases identified by the optical fibre sensor: 1) an initial soil-fibre matching phase identifying the beginning of saturation and release of previously accumulated strains; 2) fully coupled soil-fibre phase characterized by a rapid slope deformation with no external signs, represented by a steady increase in sensor strain; 3) partially-coupled soil-fibre phase which marks the first appearance of a tension crack and the consequent sharp increase in sensor strain; 4) postcollapse uncoupled soil-fibre phase in which residual friction between the sensing cable and soil induces strain on the cable.

In comparison, in the results of the measurements carried out in this work, three phases can be identified. Episodes, common to all six experiments can be summarized here as:

- Initiation of instability $\left(t_{i}\right)$ identified by the increasing trend in amplitude and frequency of the recorded phase difference signal. The oscillation of the signal is some cases quite prominent, while in others it is weaker and accompanied by some noise. However, it is present in the signals recorded during all of the six experiments. This phase corresponds to a combination of phases 1) and 2) reported by Schenato et al. (2017) as no clear limit between cable relaxation and fully coupled interaction can be identified on the oscillation trends in Fig. 4. Nevertheless, this phase indicates that modification of the state of the slope occurs at shallow depths. This episode is characterized by the absence of any visual indication of slope deterioration in the images collected during the experiments. This stage can be identified from 2 to $8 \mathrm{~min}$ before failure occurs. The response of the optical fibre sensor is likely caused by the rapid infiltration of water causing the rearrangement of soil particles and consequent redistribution of stresses. With the advancement of the experiment, the signal oscillation increases, indicated by the increase in peak prominence to width ratio (red envelope in the figures). This phase ends with a sharp increase in oscillation which marks the appearance of the first cracks in the soil. The start of this phase is highlighted in orange in the plots.

- Occurrence of failure, $\left(t_{f}\right)$, identifying the first failure of soil, preceded by opening of tension cracks. This instant is the first visual 
Table 1

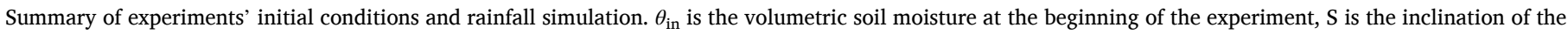
simulated landslide, $\mathrm{n}$ is the porosity of the soil, $\mathrm{H}$ is the simulated rainfall intensity.

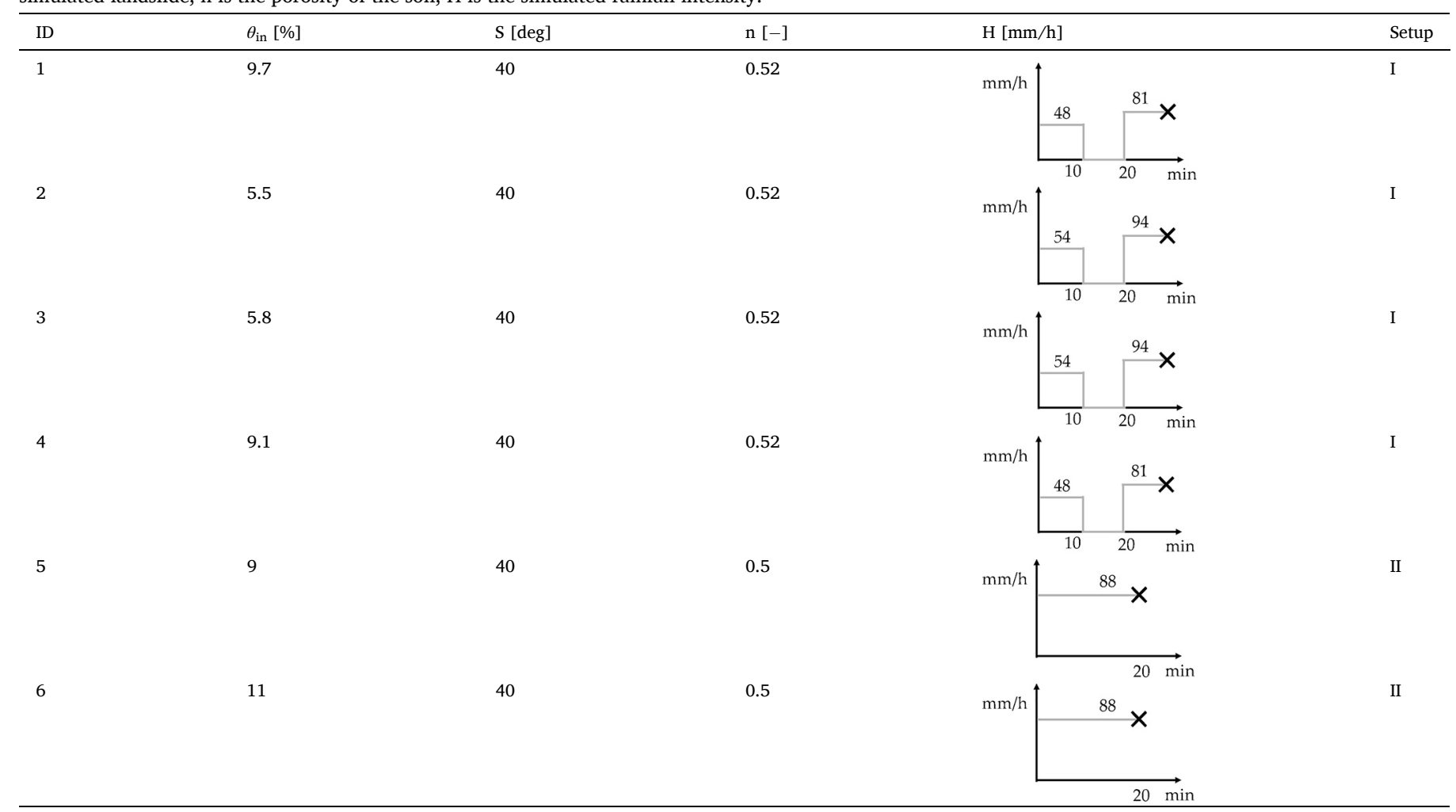

indication of slope failure and is characterized by a peak in sensor signal oscillation, outlined in Fig. 4 a-f by a red envelope. This instant corresponds to the initiation of phase 3 ) reported by Schenato et al. (2017). The sharp increase observed here is caused by the high instantaneous strains applied to the sensors and/or the partial decoupling between soil and sensing cable. The failure is marked by the start of the red highlight in the plots.

- Post-failure episode, $\left(t_{\mathrm{pf}}\right)$, during which the sensors indicate the consecutive failure of the upper portions of soil. Even though failure has already occurred here, the sensors detect the impacts of failing soil. This phase is identified as the post-failure phase, during which the optical fibre sensor signal detects the various soil detachments, marked by $t_{p f}$ in the figures. Similar episode is identified by Schenato et al. (2017) as 4) post-collapse uncoupled soil-fibre phase.

TDR readings during all experiments indicate that failure generally occurs before the complete saturation of the soil. This suggests that the destabilization process is controlled by the rapid wetting front propagation, compared to the works of Schenato et al. (2017) and Olivares et al. (2009), where the simulation involves the formation of a perched water table. The mode of failure observed in this work corresponds to what has been described by Schilirò et al. (2019) for experiments with similar initial soil moisture content and sandy soil composition.

\subsection{Spatial response}

The position of the optical fibre sensors within the slope reveals that in the cases in which the sensors are positioned at two different depths at the lower section of the slope (experiments 1-4, Setup I, Fig. 4 a-d) the uppermost sensor (I.B) reacts to the accelerating terrain in a more pronounced manner, while the sensor installed at the bottom (I.A) is characterized by a weaker detection of the same process. The initiation time, $t_{i}$ and failure time, $t_{f}$ at the two depths coincide in experiments 1 and 4, while during experiment 2 only the initiation instants indicated by the two sensors are concurrent. Hence, a certain difference between those cases can be outlined. During experiments 1 and 4 the entire cross section of the slope is involved in the process, while the delay of the initiation phase during experiment 2 indicates the early activation of the uppermost layer of soil, followed by the deeper one. It is worth noting that both experiments 1 and 4 are characterized by similar initial conditions in terms of soil moisture as well as simulated rainfall intensity and pattern. On the other hand, during experiment 3, the lowermost sensor (I.A) only slightly identifies a post-failure episode, while no clear initiation and failure instants could be outlined. Instead, the sensor installed in the shallow layer is characterized by a rather pronounced signal oscillation. This suggests that the failure process occurs within the shallow soil layer similarly to experiment 2 . In fact, those two cases initiate under similar soil moisture conditions - with values lower that experiments 1 and 4, respectively.

Experiments 5 and 6 present some rather interesting differences in the behaviour of the slope in its different sections along the slope. Looking at experiments 5 and 6 (Setup II, Fig. 4 e,f) the delay in the optical fibre sensor response can be identified. The evident shift in the response of the sensing cables identifies the succession of events development from the toe of the landslide to its upper sections. Both the initiation phase and time of failure are detected first by the sensors located at the lower sections of the slope (II.A). This is followed by the sensors placed in the middle of the slope (II.B), while the uppermost sensors (II.C) hardly indicate any sign of instability if not at a very advanced stages of the experiment (Fig. 4f, II.C). Instead, those sensors appear to be more "active" immediately after the start of the rainfall simulation. Signs of instability here appear before the time of failure, similarly to experiments conducted under setup I, as indicated by the increase in frequency and amplitude some minutes before the first failure. 

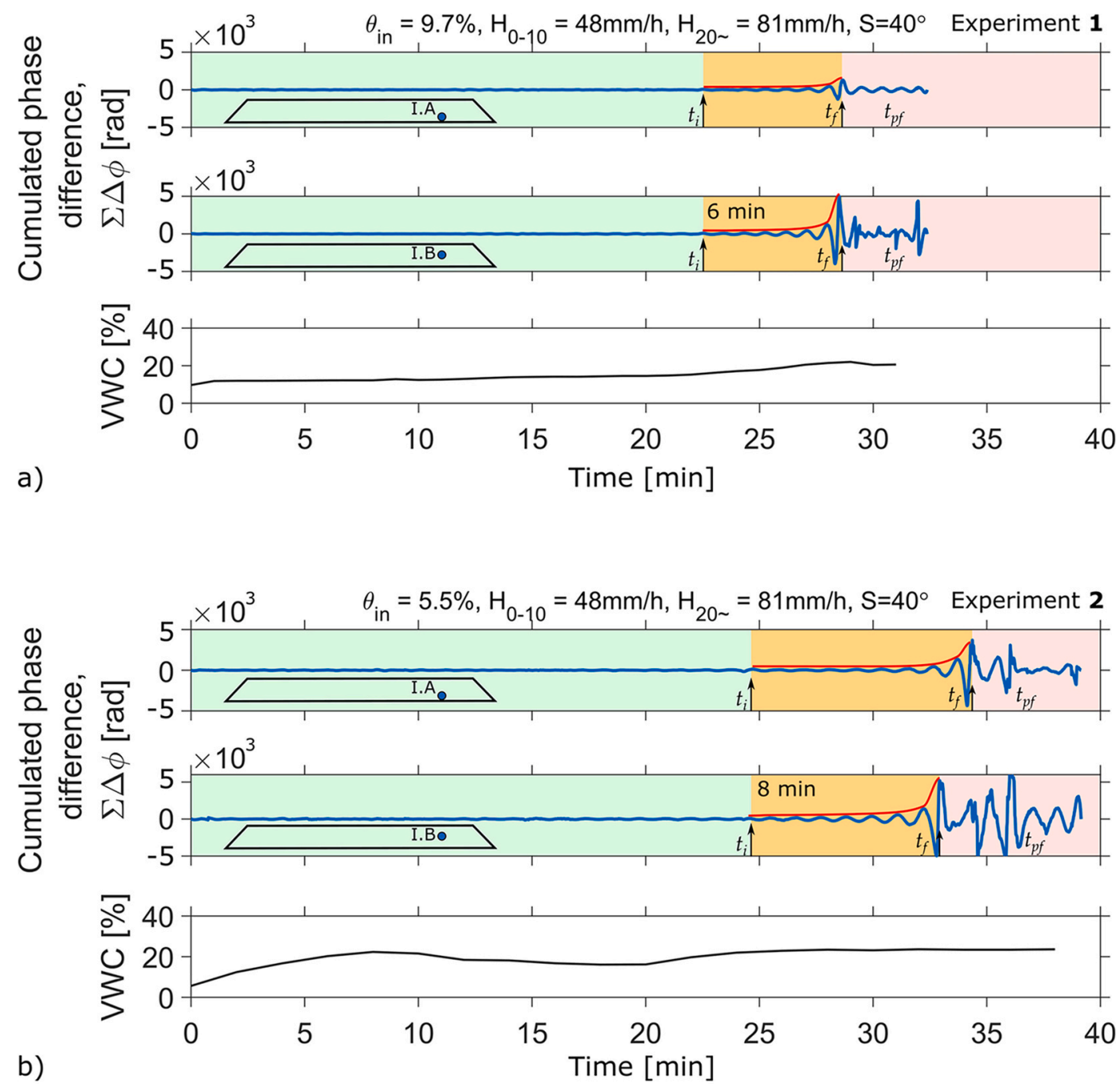

b)
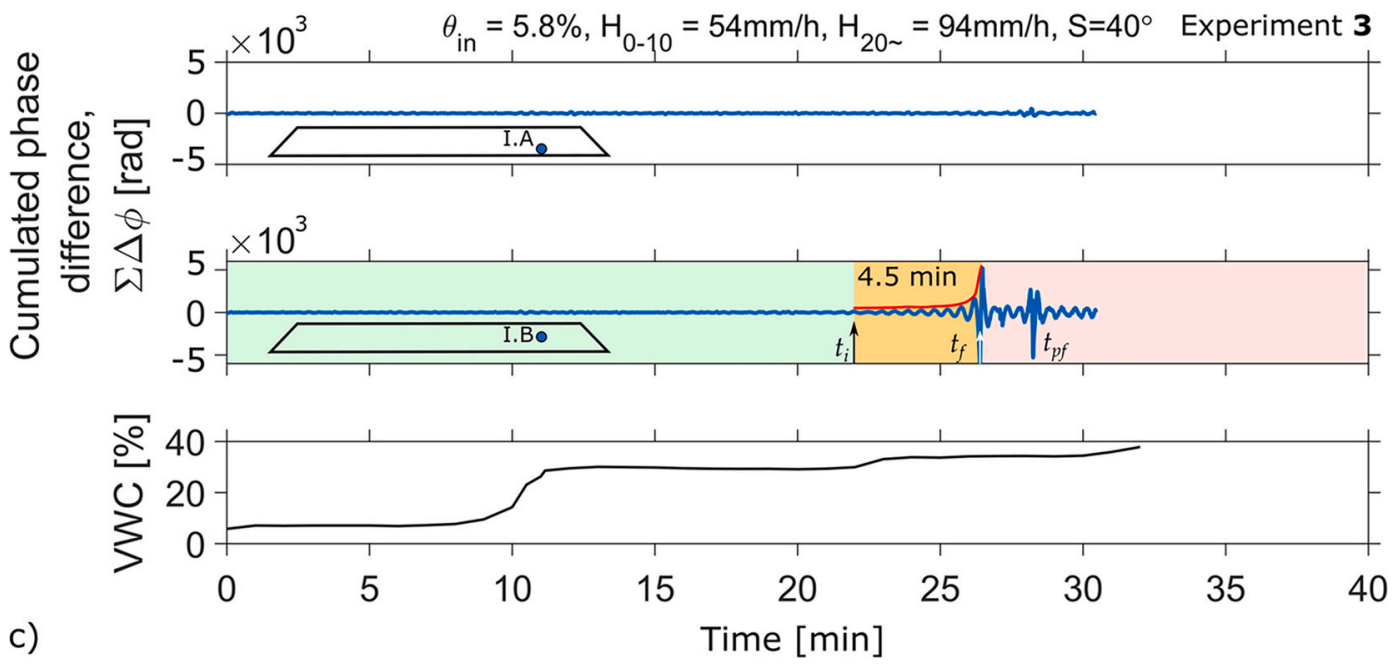

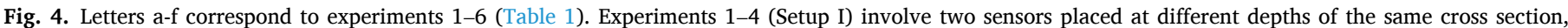

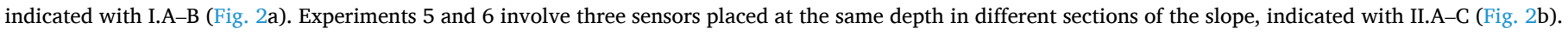

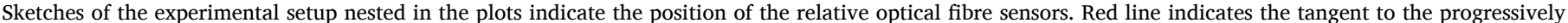

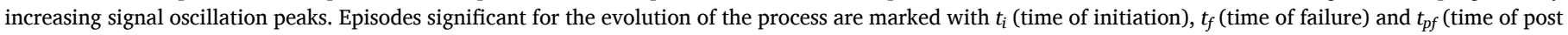

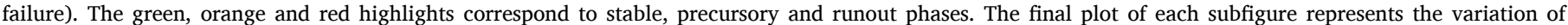
volumetric water content (VWC) during the experiment. The title of each panel summarizes the initial experimental conditions. 

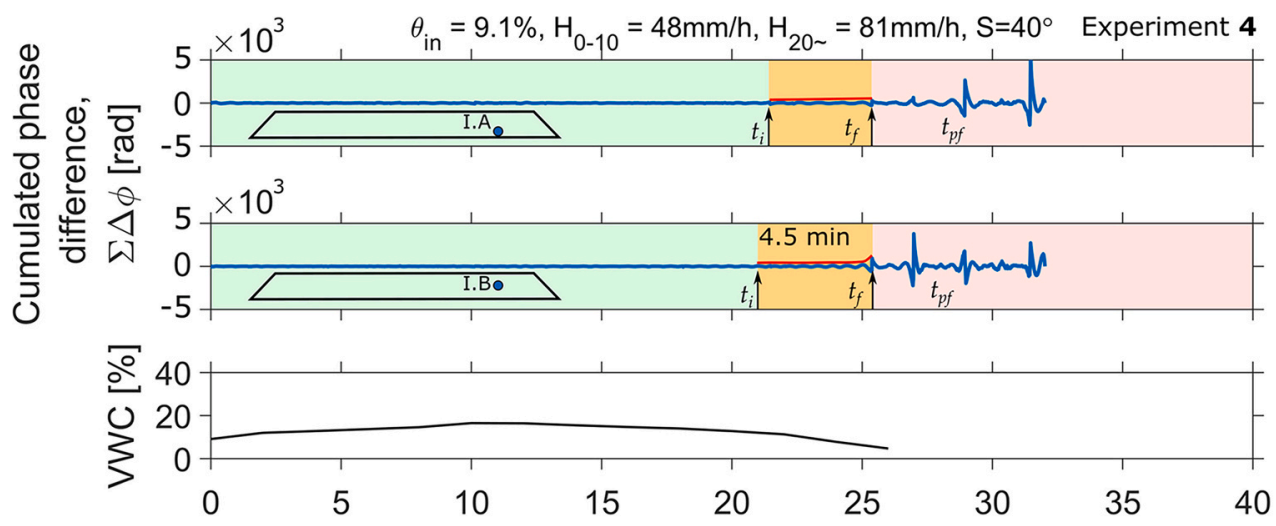

d)

Time [min]
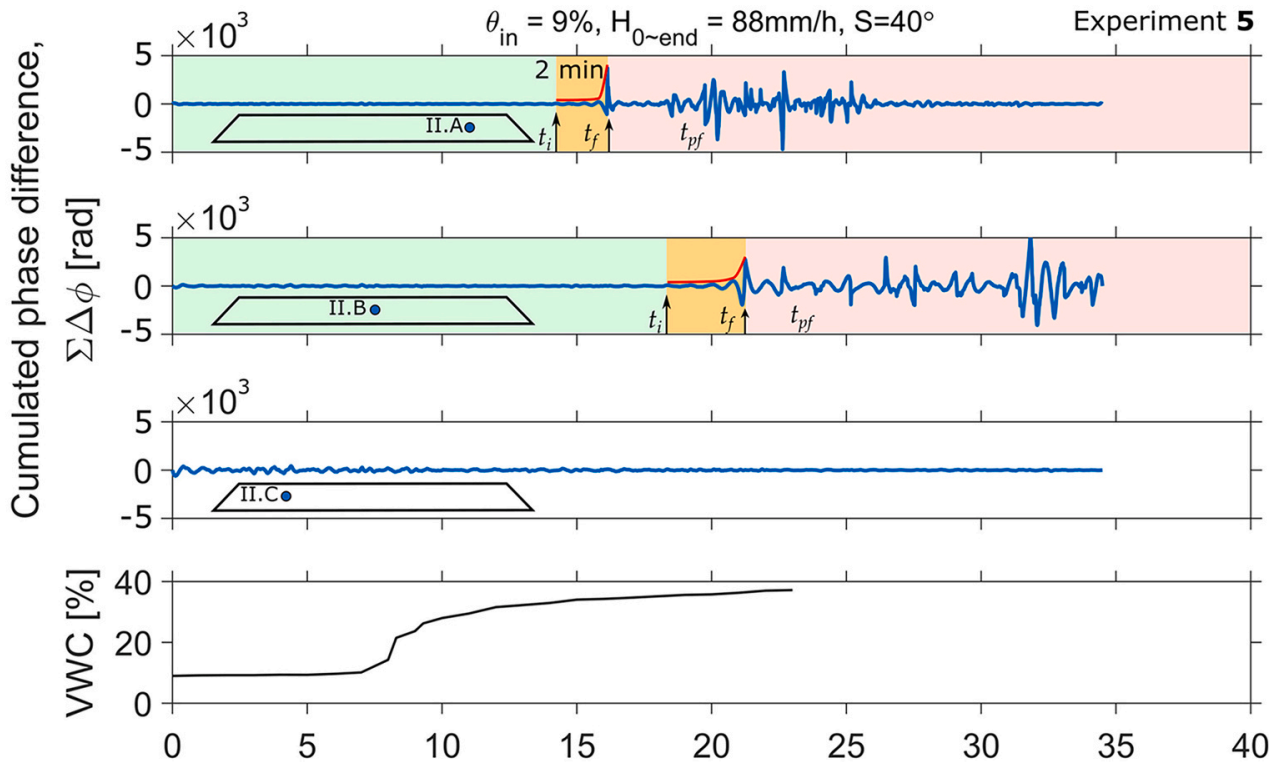

e) Time [min]

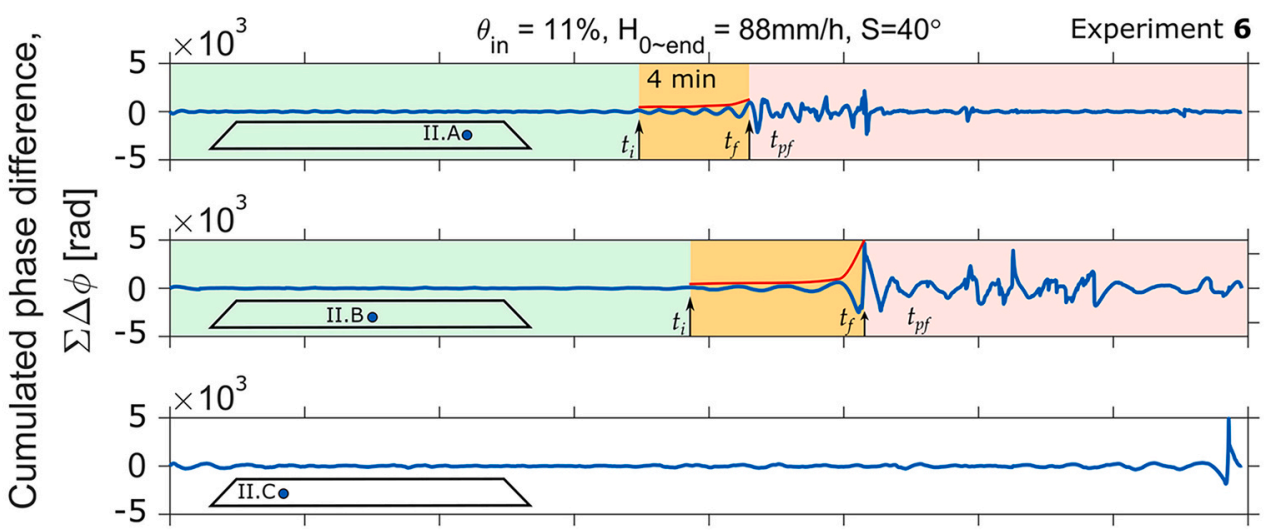

f)

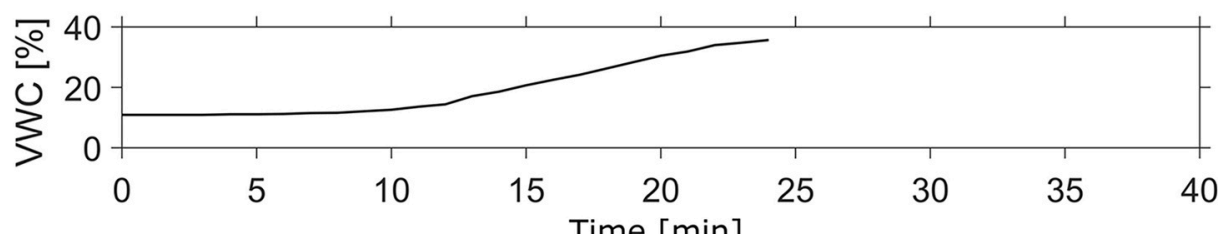

Fig. 4. (continued) 


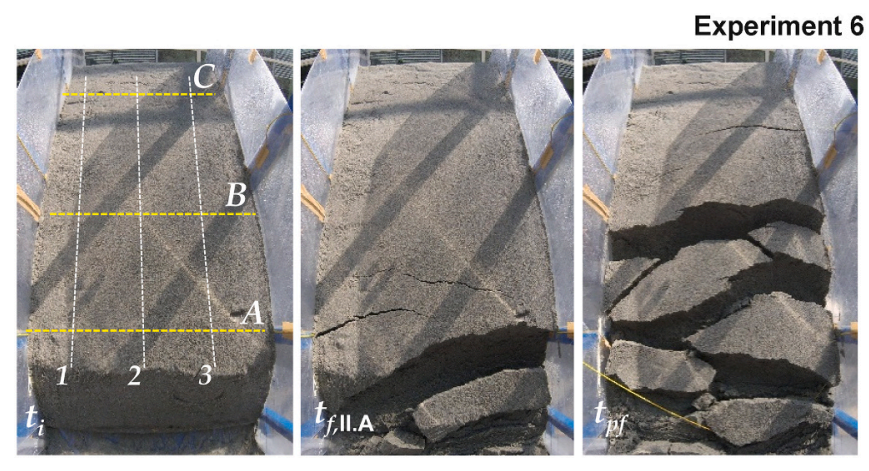

Fig. 5. An illustration of the phases of the experiments with reference to experiment 6 (Fig. 4f), experimental configuration II (Fig. 2b). From left to right: $t_{i}$ intact slope; $t_{f}$ - first failure of the slope; $t_{p f}$ - post failure phase. Yellow dashed lines indicate the position of the interferometric optical fibre sensors. White dashed lines indicate the position of the Luna ODiSI-B sensors.

\subsection{Validation}

In order to evaluate the functioning of the proposed interferometric sensing system, a comparison has been carried out with a wellestablished OFDR optical fibre sensor, the Luna ODiSI-B. A parallel measurement has been carried out during experiment 6 . Three strands of fibre optic cables were installed in the terrain, placed along the longitudinal section of the slope (Fig. 5). The strain evolution of the three strands recorded at the sections of maximum strain is plotted in Fig. 6. Black dashed lines correspond to the phases identified by the interferometric system at the lower and middle sections of the slope, respectively. The comparison indicates that the initiation of instability has been simultaneously identified by both sensors. This is illustrated by the continuous increase of strain recorded by the distributed optical fibre sensors and the increase in oscillation of the interferometric sensors. The agreement between the readings of the two sensing instruments testifies for the capabilities of the proposed sensor to compete with similar high precision instruments. The configuration of the OFDR distributed sensing used in this experiment recorded strain of up to $3000 \mu \varepsilon(0.3 \%)$ before a disruption of the sensor occurred. Comparable values were obtained by Zeni et al. (2015) for a similar experimental setup, however using a heavily coated cable. Instead, Schenato et al. (2017) report cable strain of up to $1 \%$ with robustly designed corrugated cable configuration. It must be noted that the Luna interrogator could be a suitable tool for experimental work at the laboratory scale. However, the dimensions of the instrument, its sensitivity to unfavourable meteorological conditions and dust, as well as its elevated cost could render it rather impractical for onsite installation. In this work, it was used merely for the evaluation of the functioning of the interferometric sensors.

\section{Discussion}

\subsection{Sensor layout}

Failure instants and some common episodes of failure development were correctly identified in each of the six tests presented in this work. Comparable results were obtained in similar applications (Olivares et al., 2009; Schenato et al., 2017), where however sensing cables were placed parallel to the direction of failure and different sensing technology was employed. In the present work, the signal output, being integrated over the entire sensing cable length, required the cable placement along a series of transversal cross sections of the landslide. This ensured the identification of instability at different positions along the slope, corresponding to the sensing branches. Longitudinal sensor placement as in past works, could possibly be affected by a relative slip between the soil and the sensors, even though technological solutions to ensure the proper grip have been proposed by Schenato et al. (2017) in terms of corrugated cable coating, micro-anchors installed along the cable as in the work of Iten et al. (2011) in their in-situ application, or pieces of geogrid attached to the sensing cable (Olivares et al., 2009). Cables fixed orthogonally to the direction of sliding would certainly guarantee a better soil-cable coupling, although high stresses could possibly be problematic as optical fibre cables are less resistant to shearing with respect to longitudinal deformation. On the other hand, soil-embedded fibre optic cables have previously been placed perpendicularly to the direction of landsliding in some in-situ applications. Iten et al. (2011) and Hauswirth et al. (2013) attempted to identify a boundary between a stable and unstable part of a slope by embedding an optical fibre sensor in a shallow trench. Here however, the authors did not detect any strain over the monitoring period, concluding that no movement occurred. An ingenious layout has been proposed by Brückl et al. (2013) and Lienhart (2015) who installed three $5 \mathrm{~m}$-long branches of low-coherence interferometric sensors $(\mathrm{SOFO} \otimes)$ in the shallow layer of a slow-moving deep-seated landslide. The rosette layout allowed for the description of strain and/or compression of the landslide body in three different directions, similarly to rosettes in mechanical stress analysis. This layout is particularly suitable for the slow-moving landslide with a focus on an area of $5 \mathrm{~m}$ radius as the landslide extent and activity is well-known. Instead, when an extended area is to be monitored with no clear boundaries, an extensive cable burial across a potentially unstable slope could be more appropriate. The experiments presented here indicate that placement of sensors in direct contact with soil and perpendicularly to the direction of slope failure appears to be a reasonable solution for the monitoring of shallow slope deformation. Ideally, the sensors should be placed near the failure surface or landslide boundary in order to be efficient. This is applicable mainly for the shallow soil layers of up to few meters, where excavating a burial trench would be a fairly doable task. In terms of spatial coverage, the possibility to interrogate sensors of kilometric lengths as well as multiplexing, would allow the monitoring of areas for which the landslide boundaries

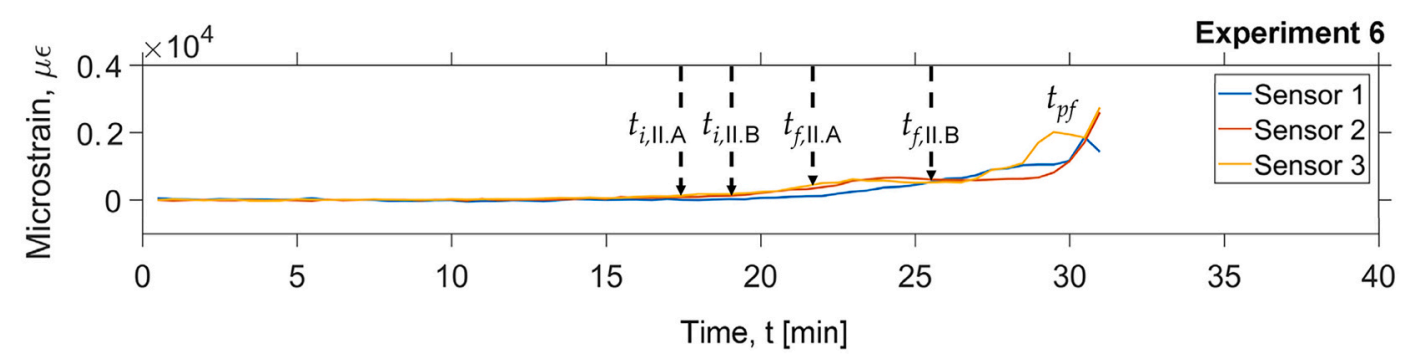

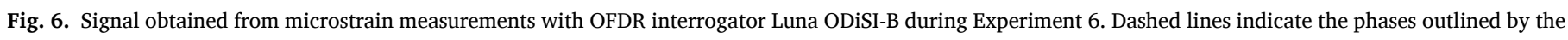
interferometric FO sensors (Fig. 4f). 
are not identified in advance.

\subsection{Sensor sensitivity}

Moreover, the sensitivity of the interferometric optical fibre sensor makes it particularly useful for monitoring of swiftly developing processes such as rainfall induced landslides. Picarelli et al. (2015) report an updated Brillouin frequency shift, that is, a new measurement each 15 min. While for some slow-moving phenomena this sort of temporal resolution would be sufficient, the abrupt nature of shallow failures certainly requires faster monitoring updates that can be easily guaranteed by the proposed interferometric sensor, featuring a wide acquisition bandwidth capability, even up to the $\mathrm{MHz}$, limited only by the adopted ADC (Analog to Digital Converter) sampling board (Sbarufatti et al., 2016). In the presented experiments the sampling frequency of the interferometric sensor, set to $20 \mathrm{kSample} / \mathrm{s}$, was wide enough to yield high precision measurements. The large bandwidth of the proposed sensor can be even further exploited by investigating the high-frequency footprint of the recorded signals. In a former work, Michlmayr et al. (2017) proposed an optical fibre sensing of slope deformation in the rage of the acoustic emissions in a rainfall induced granular slope model. The authors managed to identify some precursors of failure as early as $100 \mathrm{~s}$ prior to failure with a sampling frequency of $50 \mathrm{kHz}$. Given the possibility to reach similar or even higher sampling rates with the proposed sensing technique, testing a similar application seems promising and will be investigated further.

\subsection{Failure precursors}

Initiation of instability is identified as early as 2 to $8 \mathrm{~min}$ before any visual sing appears in the different tests, estimated as the duration between $t_{i}$ and $t_{f}$ and highlighted in orange in Fig. 4. A common question arising in downscaled model simulations is related to the correspondence between the timescales of the simulations and that of a potential full-size phenomenon. As a general rule, Iverson (2015) stated that the larger the experimental setup is, the weaker the possible scale effects will be, with reference to the velocity of a moving landslide body. For what concerns the infiltration and redistribution of water, the velocity of the process will likely be controlled by the dimensions of the landslide body, its composition in terms of granulometric distribution, as well as the rainfall rates provoking the failure. Considering the limited thickness of the model ( $0.15 \mathrm{~m}$ against typical shallow landslide depth $<2 \mathrm{~m}$ ) as well as the excessive rainfall rates simulated in the laboratory, a time scaling factor of more than 10 could be a reasonable approximation for a full-size phenomenon. In this respect, the proposed sensors could be implemented in an early warning system, for instance, based on rainfall thresholds, similarly to the work of Abraham et al. (2020), where quantitative information of slope deformation was obtained with MEMS-based tiltmeters.

\subsection{Applicability}

Typical in-situ limitations of optical fibre sensing systems include temperature compensation, which was not necessary during the experimental tests presented here and therefore, a simple telecommunications cable was used. Instead, in real-scale installations temperature changes could be rather significant, and temperature compensation would therefore be required. A potential elegant solution is the concurrent use of a tight cable and a loose one in the same carrier as in the SOFO sensor designed by Inaudi (2004). The loose sensor measures temperature changes only, which is then used to cancel out this effect from the integral measurement of the tight counterpart. The availability of a cable with both sensing and reference fibres (a tight and a loose one) will further allow one to ignore additional stabilization of the reference fibre. Once the sensor is buried, the reference loose fibre will only sense the variations of the soil temperature to be used for compensation of the sensing fibre in order to retrieve information on the slope deformation only by the tight one.

The integral nature of the presented interferometric approach can be seen a shortcoming in comparison to distributed fibre optic monitoring systems, such as BOTDA and BOTDR, that provide the entire strain profile in detail along the sensing cable with centimetre spatial resolution, as it does not allow to localize the origin of strain along the fibre length. This limitation can, however, be overcome by adding a multiplexing functionality to the interferometric interrogator so that tens of sensing fibres sections could be exploited to cover the entire area of interest. Alternatively, two integral interferometric sensors can be exploited in a counter-propagating scheme allowing for event localization as recently demonstrated by (Di Luch et al., 2019). In a follow-up work, a novel interrogation technique named Brillouin Optical Correlation Domain Analysis (BOCDA) (Morosi et al., 2017) will be exploited that can recover the entire strain profile along the deployed sensing fibre with centimetric-spatial resolution. In both upgraded cases, the integral nature of the proposed approach is preserved, which would guarantee an intrinsic higher sensitivity in the detection of the onset of landslide phenomena with respect to BOTDA and BOTDR systems. A comparison between the sensors presented here and parallel measurements with Luna ODiSI-B, a OFDR sensing device, illustrated that the two technologies yield comparable results in terms of slope failure detection under laboratory conditions. The interferometric interrogating system described here could, however, bring the costs of optical fibre-based monitoring approach down to an order of magnitude while maintaining a high sensitivity to strain phenomena. While the Luna ODiSI-B and similar interrogating units could cost up to $€ 80 \mathrm{k}-€ 100 \mathrm{k}$, the system proposed here, featuring several sensing branches could be set up for as little as $€ 5 \mathrm{k}$. While some sensing systems require high performing laser source (narrow linewidth) to operate over long distances, the working principle of the proposed sensing scheme, based on separate sensing and reference arms, renders it less dependent on the quality of the input laser source and hence, the possibility to use an economic alternative decreases the total expenses, while maintaining competitive sensing performance.

The sensing scheme used in the laboratory experiments is such that it requires the continuous connection between interrogating unit and sensors in order to maintain reference values. In terms of in-situ measurements, this might be a shortcoming as the interrogating unit must be continuously kept on site. On the other hand, when dealing with rainfallinduced landslides, and in particular, if an integrated early warning system is to be designed, continuous monitoring would be, nevertheless, required. In the prospect of monitoring a slow-moving slope, the requirement of keeping the interrogator on site can be overcome by a modification of the interrogating scheme, which will permit the conservation of a reference reading, and consequently the interrogation can be carried out epoch-wise. The sensing scheme can be upgraded without a particular increase in costs, in order to be able to carry out absolute measures of strain allowing for the interrogator to register increments of strain also for the period in which it was detached from the sensing part. To do so, it is sufficient to apply a direct "sawtooth" modulation on the laser's current, inducing a modification in its wavelength (Udd and Spillman Jr, 2011). Therefore, the receiver used here and based on a $3 \times$ 3 coupler, will measure the variation in phase within the duration of the sawtooth. As long as this duration is maintained fixed, the measurement becomes absolute. Detaching the interferometer and repeating the measure after a long period of time, a change in phase registered within the duration of the sawtooth will identify a corresponding change in strain. The mathematical formulation and schematical representation of this modulation can be consulted in Morosi et al. (2016). Note that the modulation in the cited work was introduced with a different purpose. The principle however is the same.

A number of feasibility aspects must be considered in case of an onsite installation. Such aspects include, for instance, the proper positioning of sensing cables underground as well as the efficient soil-cable 
adherence. A potential solution to this is the excavation of shallow trenches and the employment of anchors which will ensure friction between the soil and the cable as mentioned earlier. Other practical considerations include the safe and accessible installation of the interrogating unit and laser source, together with the provision of electrical current to supply continuous monitoring. The possibility to interrogate the cable from a distance permits the acquisition components to be installed away from the sensing location, where shelter and electrical current are available. Depending on the case study, continuous monitoring might not be necessary. In such a case, the acquisition components can be detached after a reading is taken and brough back to the site for the following reading. This implies that accessibility to the case study should be ensured when a reading is scheduled - an aspect which can be problematic in highland environments, especially during the winter season. Finally, data storage and transmission are matters of non-negligible importance as well. Great amounts of numerical data can be difficult to manage from this point of view, especially if a continuous monitoring system is the objective.

The experimental tests presented here were carried out in a noncohesive soil. Thus, the applicability of the sensors at this stage can be considered valid for soil-like materials even though monitoring of cohesive soils can potentially be monitored as well, despite the potentially different failure mechanisms. Instead, loose coarse material which often constitute debris flows, would be difficult to monitor using direct cable placement as adherence between the sensors and the composing material is unlikely to be ensured as this medium tends to be less homogeneous with respect to soil-like materials.

\section{Conclusions}

In this work we presented the results of six experimental tests, investigating the possibility to employ a novel sensor for rainfallinduced landslide monitoring. Different test configurations included the positioning of the optical fibre cables at different locations along the slope and in depth. Several evolutionary phases could be determined through the use of the proposed sensing system, where the most significant is the clear identification of a pre-failure period, two to eight minutes before morphologic signs of instability became visible on the slope surface. Sensors placed along different transversal cross section indicated that instability develops in a different manner at different positions along the slope. Sensors placed at different depths along the same transversal cross-section revealed a similar behaviour but with a temporal delay in the detection of failure, indicating that first signs of instability were more pronounced in the shallow soil layers. Those indications vouch for the ability of the proposed technology to detect early instability precursors as well as to correctly identify the succession of processes leading to slope failure. A parallel measurement with a wellestablished OFDR sensor demonstrated a good agreement between the two systems in the detection of slope movement. The optical fibre interferometric sensor could therefore be used for the detection of slope movements in soil-like materials. Its use offers high sensitivity to strain with a simple optical fibre cable at the fraction of what a commercially available distributed strain sensing device would normally cost. This should eventually allow for the installation of a higher number of sensors which is certainly suitable for a widespread phenomenon such as shallow landslides. The proposed monitoring approach could be efficient in detecting mass movements at different depths, depending on the installation feasibility, but likely not more than few meters where excavation and placement would become unpractical. Although the sensing system is currently unable to identify the location of strain along the cable, a newly developed interrogating scheme will soon update and improve the proposed interferometric sensor.

\section{Author statement}

Vladislav Ivanov and Laura Longoni conceptualized the study. All authors participated in the preparation and execution of the experiments. Maddalena Ferrario and Marco Brunero were in charge of sensor curation and data acquisition. Vladislav Ivanov and Diego Arosio analysed and interpreted the data. Vladislav Ivanov wrote and revised the manuscript. Laura Longoni and Monica Papini supervised the research. All authors reviewed the manuscript.

\section{Declaration of Competing Interest}

The authors declare that they have no known competing financial interests or personal relationships that could have appeared to influence the work reported in this paper.

\section{Acknowledgements}

The authors acknowledge the support provided by Fondazione CARIPLO through funding the project MHYCONOS, grant number 20170737.

\section{References}

Abraham, M.T., Satyam, N., Bulzinetti, M.A., Pradhan, B., Pham, B.T., Segoni, S., 2020. Using field-based monitoring to enhance the performance of rainfall thresholds for landslide warning. Water 12, 3453. https://doi.org/10.3390/w12123453.

Boffi, P., Ferrarese, G., Ferrario, M., Malavasi, S., Mastronardi, M.V., Mattarei, M., 2019. Coherent optical fiber interferometric sensor for incipient cavitation index detection. Flow Meas. Instrum. 66, 37-43. https://doi.org/10.1016/j. flowmeasinst.2018.11.005.

Brückl, E., Brunner, F., Lang, E., Mertl, S., Müller, M., Stary, U., 2013. The Gradenbach Observatory-monitoring deep-seated gravitational slope deformation by geodetic, hydrological, and seismological methods. Landslides 10, 815-829. https://doi.org/ 10.1007/s10346-013-0417-1.

Di Luch, I., Ferrario, M., Brunero, M., Boffi, P., Beligni, A., Sbarufatti, C., 2019. Coherent Fiber Optic Sensors for Impact Feature Assessment in Glass Fiber Reinforced Plastic (GFRP). In: The European Conference on Lasers and Electro-Optics. Optical Society of America ch_p_27. https://www.osapublishing.org/abstract.cfm?uri=cleo_ europe-2019-ch_p_27.

Ferrario, M., Mattarei, M., Boffi, P., Martinelli, M., 2016. A software-defined coherent fiber optic sensor for manufacturing machine diagnostic. In: 2016 IEEE Sensors Applications Symposium (SAS). IEEE, pp. 1-5. https://doi.org/10.1109/ SAS.2016.7479852.

Hauswirth, D., Iten, M., Puzrin, A., 2013. Detection of ground movements using soilembedded distributed fiber optic sensors. In: Geotechnical and geophysical site characterization 4: Proceedings of the 4th International Conference on Site Characterization ISC'4. CRC Press, pp. 579-586.

Ho, Y.-T., Huang, A.-B., Lee, J.-T., 2006. Development of a fibre Bragg grating sensored ground movement monitoring system. Meas. Sci. Technol. 17, 1733. https://doi.org/ 10.1088/0957-0233/17/7/011.

Hojat, A., Arosio, D., Ivanov, V.I., Loke, M.H., Longoni, L., Papini, M., Tresoldi, G., Zanzi, L., 2020. Quantifying seasonal 3D effects for a permanent electrical resistivity tomography monitoring system along the embankment of an irrigation canal. Near Surf. Geophys. 18, 427-443. https://doi.org/10.1002/nsg.12110.

Huang, A.-B., Lee, J.-T., Ho, Y.-T., Chiu, Y.-F., Cheng, S.-Y., 2012a. Stability monitoring of rainfall-induced deep landslides through pore pressure profile measurements. Soils Found. 52, 737-747. https://doi.org/10.1016/j.sandf.2012.07.013.

Huang, C.-J., Chu, C.-R., Tien, T.-M., Yin, H.-Y., Chen, P.-S., 2012b. Calibration and deployment of a fiber-optic sensing system for monitoring debris flows. Sensors 12, 5835-5849. https://doi.org/10.3390/s120505835.

Huntley, D., Bobrowsky, P., Qing, Z., Sladen, W., Bunce, C., Edwards, T., Hendry, M., Martin, D., Choi, E., 2014. Fiber optic strain monitoring and evaluation of a slowmoving landslide near Ashcroft, British Columbia, Canada. In: Landslide science for a safer geoenvironment. Springer, pp. 415-421. https://doi.org/10.1007/978-3-31904999-158.

Inaudi, D., 2004. SOFO sensors for static and dynamic measurements. In: Proceedings of the 1st FIG International Symposium on Engineering Surveys for Construction Works and Structural Engineering. Citeseer.

Iten, M., Puzrin, A.M., Schmid, A., 2008. Landslide monitoring using a road-embedded optical fiber sensor. In: Smart Sensor Phenomena, Technology, Networks, and Systems 2008. International Society for Optics and Photonics, p. 693315. https:// doi.org/10.1117/12.774515.

Iten, M., Hauswirth, D., Puzrin, A.M., 2011. Distributed fiber optic sensor development, testing, and evaluation for geotechnical monitoring applications. In: Smart Sensor Phenomena, Technology, Networks, and Systems 2011. International Society for Optics and Photonics, p. 798207. https://doi.org/10.1117/12.881228.

Ivanov, V., Arosio, D., Tresoldi, G., Hojat, A., Zanzi, L., Papini, M., Longoni, L., 2020a. Investigation on the Role of Water for the Stability of Shallow Landslides-Insights from Experimental Tests. Water 12, 1203. https://doi.org/10.3390/w12041203.

Ivanov, V., Radice, A., Papini, M., Longoni, L., 2020b. Event-scale pebble mobility observed by RFID tracking in a pre-Alpine stream: a field laboratory. Earth Surf. Process. Landf. 45, 535-547. https://doi.org/10.1002/esp.4752. 
Iverson, R.M., 2015. Scaling and design of landslide and debris-flow experiments. Geomorphology 244, 9-20. https://doi.org/10.1016/j.geomorph.2015.02.033.

Kogure, T., Okuda, Y., 2018. Monitoring the vertical distribution of rainfall-induced strain changes in a landslide measured by distributed fiber optic sensing with Rayleigh backscattering. Geophys. Res. Lett. 45, 4033-4040. https://doi.org/ 10.1029/2018GL077607.

Li, J., Correia, R., Chehura, E., Staines, S., James, S.W., Tatam, R.P., 2010. A fibre bragg grating-based inclinometer system for ground movement measurement. In: Fourth European Workshop on Optical Fibre Sensors. International Society for Optics and Photonics, p. 765314. https://doi.org/10.1117/12.866334.

Li, F., Zhao, W., Xu, H., Wang, S., Du, Y., 2019. A highly integrated BOTDA/XFG sensor on a single fiber for simultaneous multi-parameter monitoring of slopes. Sensors 19, 2132. https://doi.org/10.3390/s19092132.

Lienhart, W., 2015. Case studies of high-sensitivity monitoring of natural and engineered slopes. J. Rock Mech. Geotech. Eng. 7, 379-384. https://doi.org/10.1016/j. jrmge.2015.04.002.

Longoni, L., Ivanov, V.I., Brambilla, D., Radice, A., Papini, M., 2016. Analysis of the temporal and spatial scales of soil erosion and transport in a mountain basin. Italian J. Eng. Geol. Environ. 16, 17-30. https://doi.org/10.4408/IJEGE.2016-02.0-02.

Martinelli, M., 1989. A universal compensator for polarization changes induced by birefringence on a retracing beam. Opt. Commun. 72, 341-344. https://doi.org/ 10.1016/0030-4018(89)90436-7.

Martinelli, M., Ferrario, M., 2013. Synoptic optical fibre sensor. Patent W02013179118A1.

Mathworks, 2019. Signal Processing Toolbox. https://it.mathworks.com/help/ pdf doc/signal/signal ref.pdf (accessed January 2021).

Michlmayr, G., Chalari, A., Clarke, A., Or, D., 2017. Fiber-optic high-resolution acoustic emission (AE) monitoring of slope failure. Landslides 14, 1139-1146. https://doi. org/10.1007/s10346-016-0776-5.

Minardo, A., Picarelli, L., Avolio, B., Coscetta, A., Papa, R., Zeni, G., Di Maio, C., Vassallo, R., Zeni, L., 2014. Fiber optic based inclinometer for remote monitoring of landslides: on site comparison with traditional inclinometers. In: Geoscience and Remote Sensing Symposium (IGARSS), 2014 IEEE International. IEEE, pp. 4078-4081. https://doi.org/10.1109/IGARSS.2014.6947382.

Montgomery, D.R., Dietrich, W.E., 1994. A physically based model for the topographic control on shallow landsliding. Water Resour. Res. 30, 1153-1171. https://doi.org/ 10.1029/93WR02979.

Morosi, J., Mattarei, M., Ferrario, M., Boffi, P., Martinelli, M., 2016. Coherent Fiber Optic Temperature Sensor based on VCSEL direct modulation. In: In 2016 Fotonica AEIT Italian Conference on Photonics Technologies, June 2016, paper 188.

Morosi, J., Ferrarlo, M., Boffi, P., Martinelli, M., 2017. Double slope-assisted Brillouin optical correlation domain analysis. In: 2017 Conference on Lasers and ElectroOptics Europe \& European Quantum Electronics Conference (CLEO/Europe-EQEC) IEEE, p. 1. https://doi.org/10.1109/CLEOE-EQEC.2017.8086885.

Olivares, L., Damiano, E., Greco, R., Zeni, L., Picarelli, L., Minardo, A., Guida, A., Bernini, R., 2009. An instrumented flume to investigate the mechanics of rainfallinduced landslides in unsaturated granular soils. Geotech. Test. J. 32, 108-118. https://doi.org/10.1520/GTJ101366.

Papini, M., Ivanov, V.I., Brambilla, D., Arosio, D., Longoni, L., 2017. Monitoring bedload sediment transport in a pre-alpine river: an experimental method. Rend. Online Soc Geol. Ital. 43, 57-63. https://doi.org/10.3301/ROL.2017.35.

Papini, M., Ivanov, V.I., Brambilla, D., Ferrario, M., Brunero, M., Cazzulani, G., Longoni, L., 2020. First steps for the development of an optical fibre strain sensor for shallow landslide stability monitoring through laboratory experiments. Appl. Geol. 197-208. https://doi.org/10.1007/978-3-030-43953-8_12.

Pecoraro, G., Calvello, M., Piciullo, L., 2019. Monitoring strategies for local landslide early warning systems. Landslides 16, 213-231. https://doi.org/10.1007/s10346018-1068-Z.

Pei, H., Cui, P., Yin, J., Zhu, H., Chen, X., Pei, L., Xu, D., 2011. Monitoring and warning of landslides and debris flows using an optical fiber sensor technology. J. Mt. Sci. 8, 728. https://doi.org/10.1007/s11629-011-2038-2.

Picarelli, L., Damiano, E., Greco, R., Minardo, A., Olivares, L., Zeni, L., 2015. Performance of slope behavior indicators in unsaturated pyroclastic soils. J. Mt. Sci. 12, 1434-1447. https://doi.org/10.1007/s11629-014-3104-3.
Rajan, G., Jinachandran, S., Xi, J., Li, H., Vinod, J.S., Moses, T., Karekal, S., Prusty, B.G., 2016. Fibre optic acoustic emission measurement technique for crack activity monitoring in civil engineering applications. In: Sensors Applications Symposium (SAS), 2016 IEEE. IEEE, pp. 1-6. https://doi.org/10.1109/SAS.2016.7479851.

Sbarufatti, C., Martinelli, L., Mattarei, M., Ferrario, M., Giglio, M., 2016. Ultrasonic strain wave acquisition by a low-cost fiber optic coherent sensor for structural health monitoring applications. In: 8th European Workshop on Structural Health Monitoring, 2016. EWSHM, pp. 930-939.

Sbarufatti, C., Beligni, A., Gilioli, A., Ferrario, M., Mattarei, M., Martinelli, M., Giglio, M., 2017. Strain wave acquisition by a fiber optic coherent sensor for impact monitoring. Materials 10, 794.

Scaioni, M., Crippa, J., Yordanov, V., Longoni, L., Ivanov, V.I., Papini, M., 2018. Some tools to support teaching photogrammetry for slope stability assessment and monitoring. In: Int. Arch. Photogramm. Remote Sens. Spatial Inf. Sci., XLII-3/W4, pp. 453-460. https://doi.org/10.5194/isprs-archives-XLII-3-W4-453-2018.

Schenato, L., 2017. A review of distributed fibre optic sensors for geo-hydrological applications. Appl. Sci. 7, 896. https://doi.org/10.3390/app7090896.

Schenato, L., Palmieri, L., Gruca, G., Iannuzzi, D., Marcato, G., Pasuto, A., Galtarossa, A., 2012. Fiber optic sensors for precursory acoustic signals detection in rockfall events. J. Eur. Optical Soc. 7 https://doi.org/10.2971/jeos.2012.12048.

Schenato, L., Palmieri, L., Camporese, M., Bersan, S., Cola, S., Pasuto, A., Galtarossa, A., Salandin, P., Simonini, P., 2017. Distributed optical fibre sensing for early detection of shallow landslides triggering. Sci. Rep. 7, 14686. https://doi.org/10.1038/ s41598-017-12610-1.

Schilirò, L., Poueme Djueyep, G., Esposito, C., Scarascia Mugnozza, G., 2019. The role of initial soil conditions in shallow landslide triggering: insights from physically based APPROACHES. Geofluids 2019. https://doi.org/10.1155/2019/2453786.

Shanafield, M., Banks, E., Arkwright, J., Hausner, M., 2018. Fiber-optic sensing for environmental applications: where we have come from and what is possible. Water Resour. Res. 54, 8552-8557. https://doi.org/10.1029/2018WR022768.

Sun, Y., Shi, B., Zhang, D., Tong, H., Wei, G., Xu, H., 2016. Internal deformation monitoring of slope based on BOTDR. J. Sens. 2016. https://doi.org/10.1155/2016/ 9496285.

Udd, E., Spillman Jr., W.B., 2011. Fiber Optic Sensors: An Introduction for Engineers and Scientists. John Wiley \& Sons.

Wang, B.-J., Li, K., Shi, B., Wei, G.-Q., 2009. Test on application of distributed fiber optic sensing technique into soil slope monitoring. Landslides 6, 61-68. https://doi.org/ 10.1007/s10346-008-0139-y.

Xu, D.-S., Yin, J.-H., 2016. Analysis of excavation induced stress distributions of GFRP anchors in a soil slope using distributed fiber optic sensors. Eng. Geol. 213, 55-63. https://doi.org/10.1016/j.enggeo.2016.08.011.

Yoshida, Y., Kashlwai, Y., Murakami, E., Ishida, S., Hashiguchi, N., 2002. Development of the monitoring system for slope deformations with fiber Bragg grating arrays. In: Proceedings of SPIE - The International Society for Optical Engineering, 4694, pp. 296-303. https://doi.org/10.1117/12.472632.

Zeni, L., Picarelli, L., Avolio, B., Coscetta, A., Papa, R., Zeni, G., Di Maio, C., Vassallo, R., Minardo, A., 2015. Brillouin optical time-domain analysis for geotechnical monitoring. J. Rock Mech. Geotech. Eng. 7, 458-462. https://doi.org/10.1016/j. jrmge.2015.01.008.

Zhang, D., Shi, B., Sun, Y., Tong, H., Wang, G., 2015. Bank slope monitoring with integrated fiber optical sensing technology in Three Gorges Reservoir Area. Eng. Geol. Soc. Territory 2, 135-138. https://doi.org/10.1007/978-3-319-09057-3_13.

Zhang, Q., Wang, Y., Sun, Y., Gao, L., Zhang, Z., Zhang, W., Zhao, P., Yue, Y., 2016. Using custom fiber Bragg grating-based sensors to monitor artificial landslides. Sensors 16, 1417. https://doi.org/10.3390/s16091417.

Zhang, C.-C., Zhu, H.-H., Liu, S.-P., Shi, B., Zhang, D., 2018. A kinematic method for calculating shear displacements of landslides using distributed fiber optic strain measurements. Eng. Geol. 234, 83-96. https://doi.org/10.1016/j. enggeo.2018.01.002.

Zhu, H.-H., Shi, B., Zhang, J., Yan, J.-F., Zhang, C.-C., 2014. Distributed fiber optic monitoring and stability analysis of a model slope under surcharge loading. J. Mt. Sci. 11, 979-989. https://doi.org/10.1007/s11629-013-2816-0.

Zhu, H.-H., Shi, B., Yan, J.-F., Zhang, J., Wang, J., 2015. Investigation of the evolutionary process of a reinforced model slope using a fiber-optic monitoring network. Eng. Geol. 186, 34-43. https://doi.org/10.1016/j.enggeo.2014.10.012. 